\title{
Chapter 10 \\ MOOCs and OER: Developments and Contributions for Open Education and Open Science
}

\author{
Maria-Soledad Ramirez-Montoya
}

\begin{abstract}
The open educational movement has provided opportunities for the advancement of higher education. This chapter is framed in the development of 12 open mass courses (MOOCs) and more than 5000 open educational resources (OER) that were produced in a macro project focused on training for energy sustainability. The MOOCs integrated innovative strategies and emerging technologies (such as gamification, challenges, biometrics, virtual reality, augmented reality, virtual and remote laboratories) and the OER were produced with scalable and accessibility properties (such as reusability, atomicity, interoperability and durability). The question that guides the chapter is: What contributions can arise from formative instances such as MOOCs and OER for open education and open science? The project method was collaborative with multidisciplinary teams of energy, production and educational innovation, who designed and implemented 12 MOOCs through the MexicoX and EdX platforms, where more than 200,000 participants enrolled in the MOOCs. Similarly, the production of more than 5000 OER is available in an open-access repository. The results show contributions to open education in the areas of open innovation, open research and open science. Findings can contribute to academic communities (students, teachers, researchers, administrators), social communities, government, business and decision makers interested in learning environments and open educational practices.
\end{abstract}

Keywords MOOC $\cdot$ OER $\cdot$ Open education - Open innovation $\cdot$ Open research $\cdot$ Open science $\cdot$ Energy

\subsection{Introduction}

Advances in communication and technology have brought new possibilities for open education. The movement toward open education requires educators to expand and update their practice to keep up with new assigned responses (Littlejohn \& Hood, 2017) and to expand the perspective of services and innovation that is required to

\footnotetext{
M.-S. Ramirez-Montoya ( $\varangle)$

Tecnologico de Monterrey, Monterrey, Mexico

e-mail: solramirez@tec.mx

(C) The Author(s) 2020

D. Burgos (ed.), Radical Solutions and Open Science, Lecture Notes

in Educational Technology, https://doi.org/10.1007/978-981-15-4276-3_10
} 
become increasingly relevant (Shivdas \& Sivakumar, 2016). However, it is important to recognize that there are still many opportunities in the open educational movement, ethical ideologies are not essential components of this movement, academics are required to develop a sense of cultures of digital participation and literacy, with the integration of technologies (Veletsianos \& Kimmons, 2012). The open education movement has had ups and downs due to the initial interest in transparency, openness, lack of reuse of open educational resources, but has increased its interest in open mass courses (MOOCs) (Pirkkalainen, Pawlowski and Pappa, 2017).

Open educational resources (OER) have been an important engine in the open educational movement. Atkins, Seely and Hammond (2007) highlight UNESCO's definition when it defines them as resources for teaching, learning and research that reside in the public domain or that have been released under a licensing scheme that protects intellectual property and allows its use publicly and freely or the generation of derivative works by others. OER are identified as complete courses, course materials, modules, books, video, examinations, software and any other tool, material, or technique used to support access to knowledge. In this sense, MOOCs can be a type of OER when they are available openly and with open licensing.

MOOCs have been studied by multiple authors (Baggaley, 2013; Bartolomé \& Steffens, 2015; Cabero, 2015; Fidalgo-Blanco, Sein-Echaluce, \& García-Peñalvo, 2016; Zheng, Chen, \& Burgos, 2018) defining them as mass dissemination courses, through online platforms for the achievement of desired learning, characterized by the use of open educational resources, in which there could be not a certificate of completion of them. This educational modality has been considered as a disruptive educational innovation that allows improving current educational practices in virtual learning contexts. Among the advantages of the MOOCs, one can enunciate the interactivity among the apprentices of the course that allows to generate learning networks, as well as a socialization of the same among the participants; the promotion and publicity that educational institutions can obtain with the dissemination and reach of MOOCs; as well as the need to propose new curricula, which grant flexibility and openness to innovative educational models such as mass open courses (Sánchez-Vera, León-Urrutia, \& Davis, 2015).

However, despite the high expectations of MOOCs, as innovative and revolutionary educational models; there are criticisms and challenges that they face. Among the criticisms mentioned (Castaño, Maiz, \& Garay, 2015; Teixes, 2015) is the lack of a pedagogical model that supports the teaching-learning process in this new work dynamic, a pedagogical model that is flexible, with contents or quality educational resources that focus on the student as the main actor of their learning, allowing to offer a more personalized and diversified teaching-learning process, which entails, in turn, to increase the motivation and decrease in the levels of desertion of the beating. Likewise, there is a lack of evaluation processes that address the needs and development of a MOOC course; the facilitation or delivery of the course is also considered a problem, due to the overcrowding that characterizes them, that is, the complicated monitoring of the performance of the registered participants.

For this reason, it has been considered to incorporate in MOOC, innovative educational strategies that help to face the aforementioned criticisms. One of them is 
gamification, which can be defined as a strategy that consists of the application of playful and game resources in an educational context (Apostol, Zaharescu, \& Alexe, 2013, Gallego-Durán, et al., 2014). Several authors (Brull \& Finlayson, 2016; Chang \& Wei, 2016; Hamari et al., 2016; Hsin, Huang, \& Soman, 2013) consider that gamification is a strategy that allows contributing to the promotion of motivation and interest of MOOC participants, as well as being an effective tool to generate the necessary commitment for the completion of the course and the improvement of the learnings.

In the potential of MOOCs, there are still technologies that could contribute to the design of these training and open education. One of them is the educational platform "T-Shaped" and the use of the "Internet of Things" to improve the accessibility, scalability and merits of online education (Jeffords et al., 2014). There are also several tools to work open knowledge: open platforms for course management, online tagging, blogs, visualization technologies and open access books, online exhibitions and institutional materials (Rojeski \& Morse, 2016).

In the field of open education, we can find three strategic areas: open innovation, open research and open science.

Open innovation was born as a new paradigm of innovation at the beginning of the year 2000, which is opposed to closed innovation in which innovations only emerged within companies, since this consists in the free transfer of knowledge between different actors such as universities, companies and the government. It is defined as a new innovation model which is characterized by being dynamic and based on knowledge (Chesbrough, 2012). Open innovation is based on helping companies' internal innovation through the use of knowledge inputs and outputs, using technologies, in order to expand their market and become more competitive (Gassmann, Enkel, \& Chesbrough, 2010; Ramírez-Montoya, 2018; Ramírez-Montoya \& García-Peñalvo, 2018). It can be said that open innovation is a new model of innovation that consists in the generation and transfer of knowledge through collaborative networks within and outside organizations, with the aim of helping to improve the products and services they offer, that are more competitive.

Open research provides potential for new discoveries and solutions to global problems, so that they automatically extend beyond the limits of an individual research laboratory. By nature, they involve and lead to collaboration among researchers. This collaboration should be established at all possible levels: institutional, national and international (Hormia-Poutanen \& Forsström, 2016). Concepts such as leadership, interorganizational learning and emphasizing the values of ethics, trust, creativity, honesty or initiative are integrated, which can be as important as-or even more than-the quantitative economic concepts traditional such as efficiency or return on investment (Martin-Rubio, Nogueira, \& Llach-Pages, 2013).

Open science links research with academic communication: from publications and research data, to code, models and methods, as well as quality evaluation based on open peer review. It is the movement that aims to make scientific research and the dissemination of data accessible at all levels. It implies the publication in open (open access) and the publication and reuse of the data generated in the investigations (open research data). Participating in open science and sharing publications and research 
data stimulates scientific work, increases its citation and impact and contributes to the advancement of science (Aleixandre-Benavent et al., 2015). However, starting to implement open science may not be so easy for all interested parties. For example, what do research funders expect in terms of open access to publications and/or research data? Where and how to publish the research data? How to ensure that the results of the research are reproducible? (Schmidt et al., 2016).

The purpose of this chapter is to present what contributions can emanate from open training practices, such as MOOCs and OER for the field of open education, within the framework of a project aimed at training in energy sustainability. The Project comes from the 266632 Bi-National Laboratory on Smart Sustainable Energy Management and Technology Training, funded by the National Council of Science and Technology (CONACYT) and by the Energy Sustainability Fund of the Secretariat of Energy of Mexico (SENER) (Fig. 10.1).

The Binational Laboratory is made up of the Tecnologico de Monterrey, the National Technological Institute of Mexico, through the National Center for Technological Research and Development (CENIDET), the National Institute of Electricity and Clean Energies (INEEL), the Arizona State University and the Berkeley Energy and Climate Institute (BECI) of the University of California at Berkeley. Within the framework of the Binational Laboratory, joint work was established with the Federal Electricity Commission (CFE), which was key to the selection of open mass courses (MOOCs), which have led to the formation of more of 200,000 participants from more than 50 countries (data from the MexicoX and EdX platforms), where the following countries stand out by number of participants: Argentina, Bolivia, Brazil, Chile, Colombia, Ecuador, Spain, the United States, Guatemala, Honduras, Mexico, the Netherlands, Paraguay, Peru, the Dominican Republic and Venezuela. Figure 10.2 shows the MOOC topics and the suggested sequence for the participants.

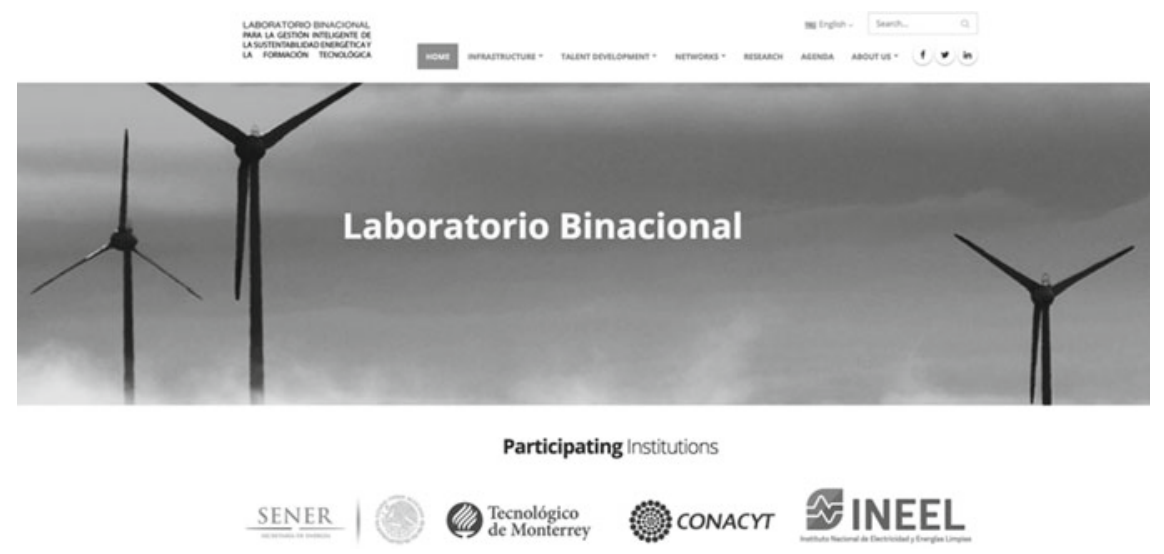

Fig. 10.1 Website portal of the project «Binational Laboratory for the Intelligent Management of Energy Sustainability and Technological Training» (https://energialab.tec.mx/en) 


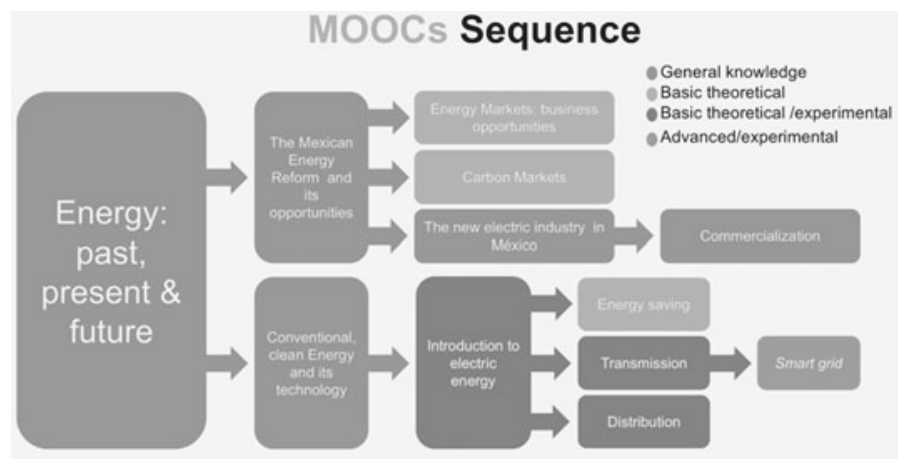

Fig. 10.2 MOOCs sequence of the binational laboratory project

Fig. 10.3 Learner's profile MOOCs

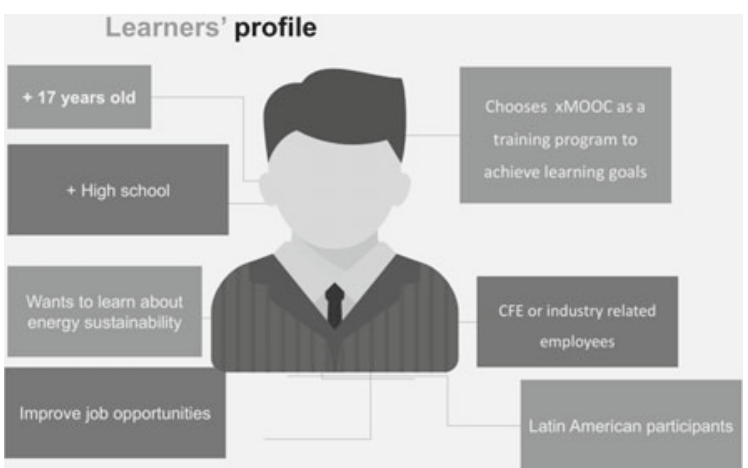

The MOOCs were designed considering a profile of participants who were interested in training programs for energy sustainability, online, older than 17 years of age and who had completed medium education (Fig. 10.3).

The question that guides the chapter is: What contributions can arise from formative instances such as MOOCs and OER for open education and open science? The method and activities are presented, how the courses were developed and linked results are analyzed open education in the areas of open innovation, open research and open science. The findings can contribute to academic communities (students, teachers, researchers, administrators), social communities, government, business and decision makers interested in learning environments and open educational practices. 


\subsection{Method and Activities}

The project method was collaborative with multidisciplinary teams that designed and implemented 12 MOOCs. The production of the MOOCs and OER was developed through multidisciplinary teams: specialists in the areas of energy, educational technology and educational research, who have worked together in the development of MOOCs and OER, as well as in putting them into operation and educational research in each one of the formative experiences.

The collaborative work was a substantial element to achieve these designs and their implementations, where two research groups with strategic focus coordinated these actions: the Energy and Climate Change Group, the School of Engineering and Sciences and the Research and Innovation Group in Education, from the School of Humanities and Education, of Tecnologico de Monterrey. The activities were developed through four axes: experimentation with prototyping practices, discovery and linking through social innovation projects), open education (with open training instances and open innovation), collaboration (co-creation and networking) and research (analyzing open practices) (Fig. 10.4).

In its beginnings (2017), the courses were taught through the open platforms MexicoX and EdX. Currently (2019), the courses are taught only on the EdX platform. The website for the promotion of the courses on the EdX platform is presented in Fig. 10.5.

The gamification was a transversal integration in the 12 MOOCs of the project, as well as emerging technologies that had not previously been worked on in MOOCs (biometrics, virtual and remote laboratories, for example). The gamification board is reflected in Fig. 10.6.

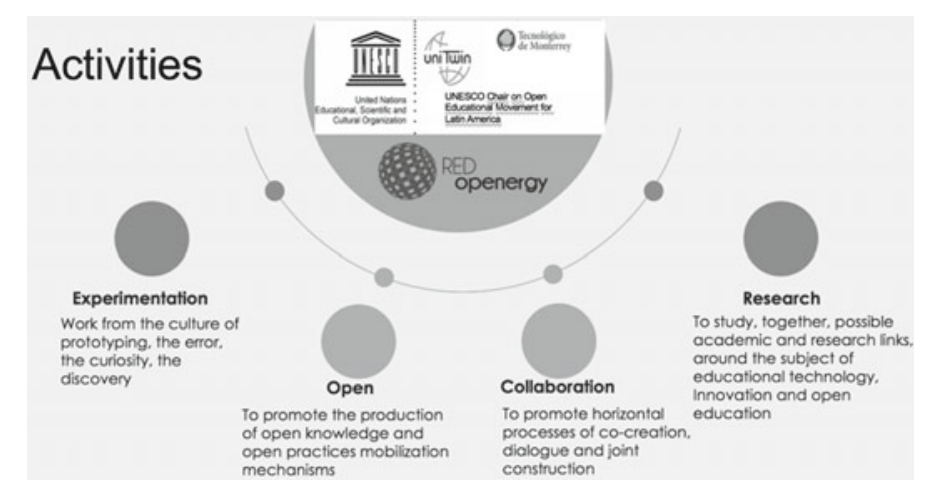

Fig. 10.4 Activities 


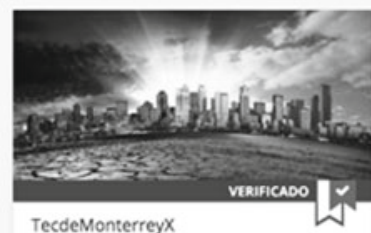

Mercados de carbono: una

forma de mitigar el cambio

En este momento

Fecha de comienzo: 22 de abril de 2019

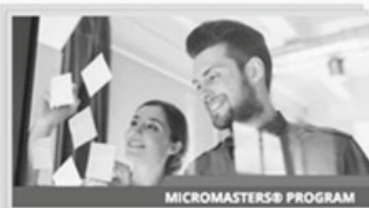

TecdeMonterreyx

Habilidades profesionales:

negociación y liderazgo

Obtén las habilidades que pondrán

en marcha tu carrera como la

En este momento

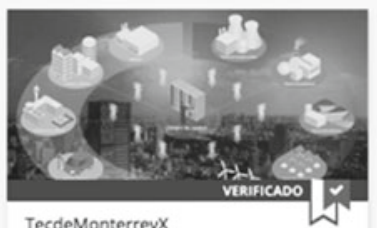

Smart grid: las redes eléctricas del futuro

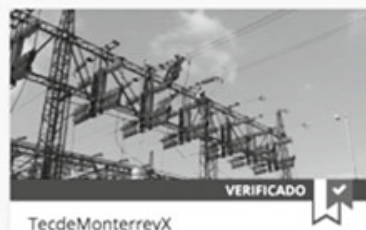

Distribución de la energía eléctrica

Fecha de comienzo: 29 de abril de 2019

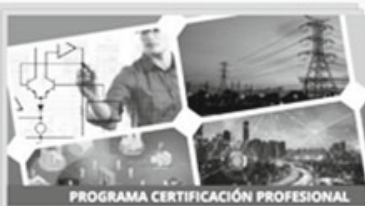

TecdeMonterreyx

Sustentabilidad energética y

la smart grid

Aprende fundamentos de la energía

eléctrica, su impacto en el cambio

En este momento

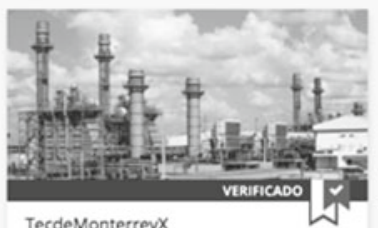

La nueva industria eléctrica en México

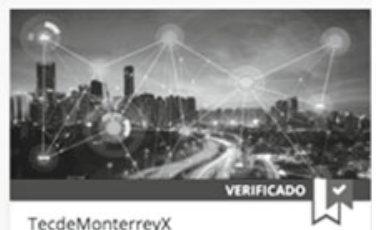

Smart grid: fundamentos técnicos

Próximamente

Fecha de comienzo: 6 de mayo de 2019

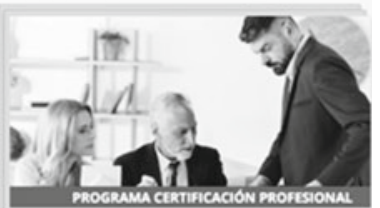

TecdeMonterreyx

Empresas familiares:

emprendimiento y liderazgo

Aprende estrategias, herramientas

y modelos para crear sinergia en la

En este momento

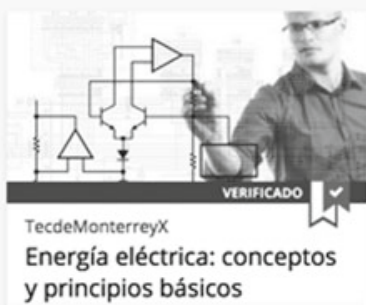

Fig. 10.5 Promotion of MOOCs on EdX platform (https://www.edx.org/es/school/tecnologico-demonterrey)

\subsection{Results}

\subsubsection{Open Innovation Category}

Open innovation is about ideas or solutions that present innovative applications of OER to create new opportunities or address existing challenges in open education (Open Education Consortium, 2019).

Three aspects are framed in this case: Interdisciplinary, collaborative and open innovation, in the project Energy Sustainability through MOOCs in the Latin American context. Outstanding innovation that brings a new approach to open education. 


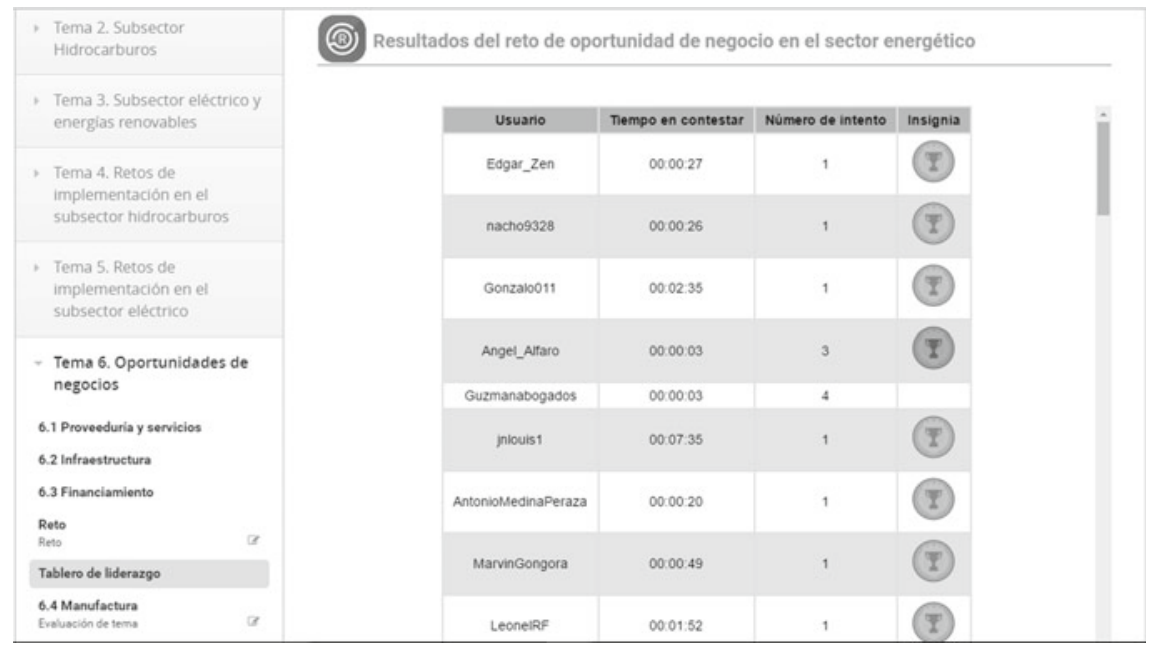

Fig. 10.6 Gamification in the MOOCs of the binational project

In the interdisciplinary, collaborative and open innovation project we work with new approaches to open education, integrating training solutions and applying OER through 12 MOOCs with innovative strategies, where we create new entrepreneurship opportunities for the challenge of energy sustainability (Molina-Gutiérrez et al., 2019).

We link the open innovation of the quad helix:

- Company (Federal Electricity Commission),

- Government (National Council of Science and Technology and Secretary of Energy of Mexico),

- Academy (Mexican institutions: Tecnologico de Monterrey, Tecnologico Nacional de Mexico, National Institute of Electricity and Clean Energies and international institutions: Arizona State University and University of California at Berkeley, as well as networks: research groups of strategic change approach Climate Change and Educational Innovation Research, Openergy Network and UNESCO Chairs/ICDE Open Educational Movement for Latin America) and

- Civil Society (more than 200,000 participants from more than 50 countries).

The objective is to support the formation of human resources specialized in energy sustainability, and develop human talent with the necessary capabilities to respond to the technological conditions prevailing in the energy value chain (Electric sector), through graduate programs, massive open online courses that will be available nationwide, and validate through competencies certification processes.

The collaborative and multidisciplinary construction was evidenced by the work of 23 members of the Energy and Climate Change Group; 36 members of the Research and Innovation in Education Group, the Openergy Network and the UNESCO-ICDE 
Open Educational Movement for Latin America; and also 22 participants of the creative team of learning environments of the Tecnologico de Monterrey.

In educational innovation, contributions are made in the integration of new resources and strategies (biometrics, gamification, challenges, virtual and remote laboratories and open educational resources) in MOOCs (Table 10.1).

In open education, the contributions are given through training with 12 MOOCs that are implemented through the open platforms MexicoX and EdX. The MOOCs have had more than 200,000 participants, from more than 50 countries, with a terminal efficiency of $14 \%$ (exceeding the average of other MOOCs).

As a result, and contribution to open education, this project generates new approach to open innovation through the development of entrepreneurial talent and contributions to the knowledge of open educational innovation. It also generates new opportunities for products and services, such as educational innovations for environments with open technologies, services and strategies for open innovation, training models with technologies, new services for open innovation, new instruments for measuring open innovations, training services: workshops, diplomas, certificates and consultancies. With the project is contributed to open innovation through the transfer and linkage with Government, Companies, Institutions, NGOs and Civil Society (Ramírez-Montoya, 2019a).

\subsubsection{Open Science Category}

An open science initiative is when a practice in which different people can collaborate and contribute, where research data, lab notes and other research processes are freely and openly available. This may include public contributions through citizen science (Open Education Consortium, 2019).

The case Bi-National Laboratory on Smart Sustainable Energy Management and Technology Training emanates from two projects funded by the National Council of Science and Technology (CONACYT) of Mexico: "Bi-National Laboratory on Smart Sustainable Energy Management and Technology Training" and "Increase in the visibility of RITEC by improving the user experience and its interoperability with the National Repository".

The project highlights the excellent results of visibility and openness of science generated as a contribution of the two projects financed with public funds granted by CONACYT. These projects were aimed at supporting the national open access regulations indicated in the General Education Law and the Organic Law of CONACYT, Article 65:

Open access means access through a digital platform and without subscription, registration or payment requirements, to research, educational, academic, scientific, technological and innovation materials, financed with public resources or that have used public infrastructure in its realization, without prejudice to the provisions on patents, protection of intellectual or industrial property, national security and copyright, among others, as well as information that, by reason of its nature or decision of the author, is confidential or reserved. 
Table 10.1 Educational innovation elements

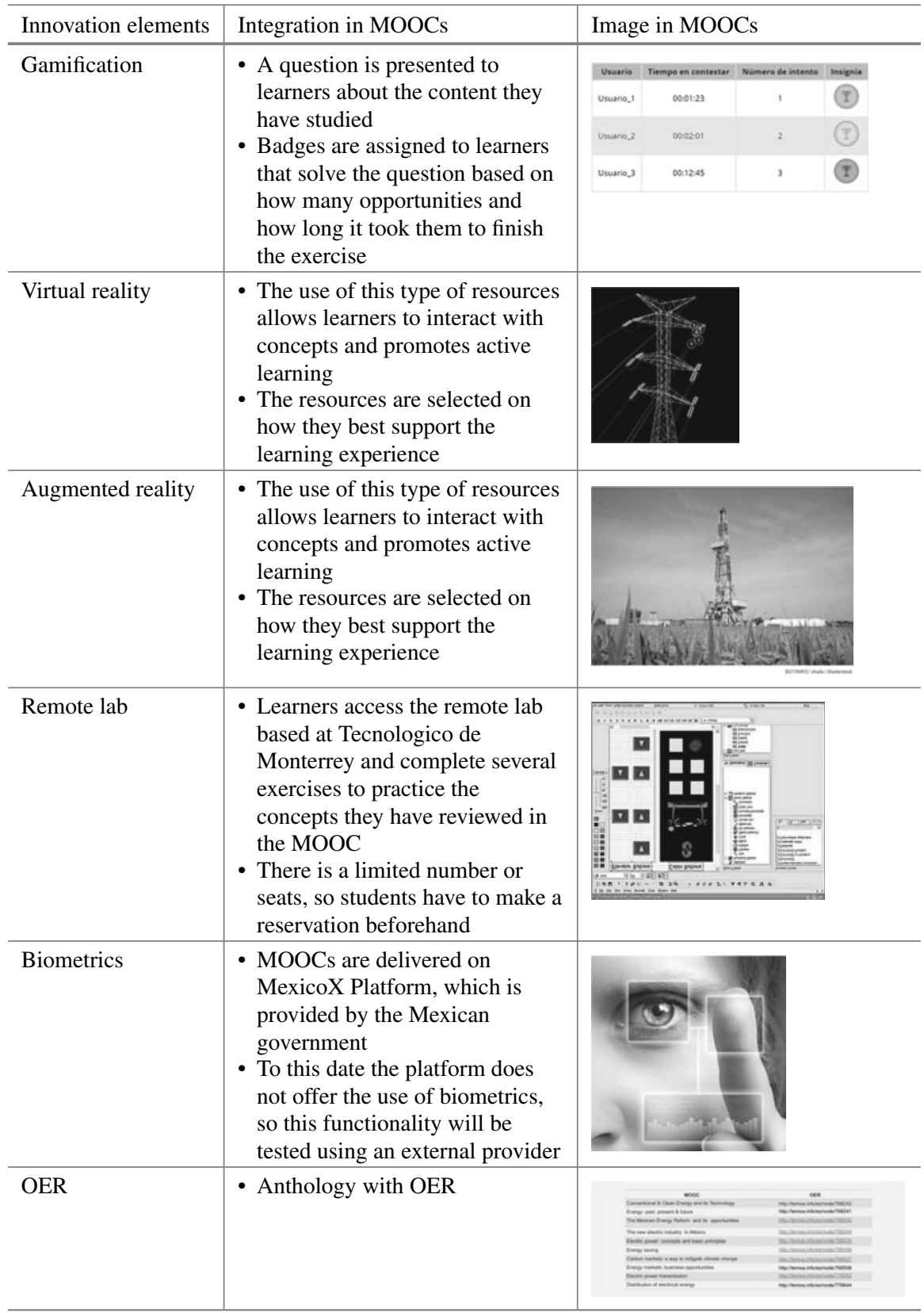


The objective of the case presented here as a good practice was aimed at researchers, undergraduate and graduate students, as well as academics, business collaborators and civil society, participating in two projects, to incorporate the use of open access practices of the scientific and academic production management model of the Tecnologico de Monterrey, in order to support the open access policy of CONACYT aimed at increasing the social appropriation of scientific and technological knowledge (Ramírez-Montoya, Burgos Aguilar, González-Pérez, \& Ceballos-Cancino, 2019).

The management model of scientific production generated by the academic community of Tecnologico de Monterrey, involves the production of open educational resources (OER), the selection of OER, the use of the Institutional Repository (RITEC) and the mobilization in open practices, such as mechanism to give visibility to academic and scientific production, as well as the consolidation of the digital identity of the Institution and its Researchers, aimed at strengthening the digital culture and open access to knowledge of our Institution and making it visible, in an open way, for the world.

Los OER were produced with scalable and accessibility properties (such as reusability, atomicity, interoperability and durability). The development of these OER took care of reusability (so that they could be reused in different educational contexts); interoperability (produced so that they were not limited to a single type of technological platform, but were easy to interact with and exchange with other technological uses); durability (the OER were produced under certain standards that guaranteed their documentation, classification and categorization; accessibility (so that they would guarantee their access and presentation); scalability (so that they could be part of modular components, to be expanded and serve a wide range of purposes in their use) and atomicity (with granulity so that they could be broken down into parts and thus generate educational entities by themselves that could be documented and identified).

Thus, from the scheme of open access practices, in the case presented here, we collaborated and built science with open instruments, open data, open innovation laboratories and open publications that are available in the institutional repository of the Tecnologico de Monterrey, with the open availability of more than 5000 OER. Of substantial importance was the collaboration of open networks (Openergy Network and the UNESCO Chairs/ICDE Open Educational Movement for Latin America) and the OpenergyLab laboratory. It is also important to connect with other open platforms such as OpenDOAR, La Referencia, Google, Remeri (Fig. 10.7).

As a result and contribution to open education, this project generates contributions to the open science through evidencing good practice of collaborative construction and visibility of knowledge, through more than 5000 OER available openly in the Ritec, built in the OpenergyLab, digitized postgraduate theses and OER produced in the binational laboratory. Open science was also contributed with a protocol for evaluating the user experience of a management model that involves visibility mechanisms of scientific production, thus contributing to incremental innovation with open systems to give visibility to knowledge and open science (Ramírez-Montoya, 2019b). 


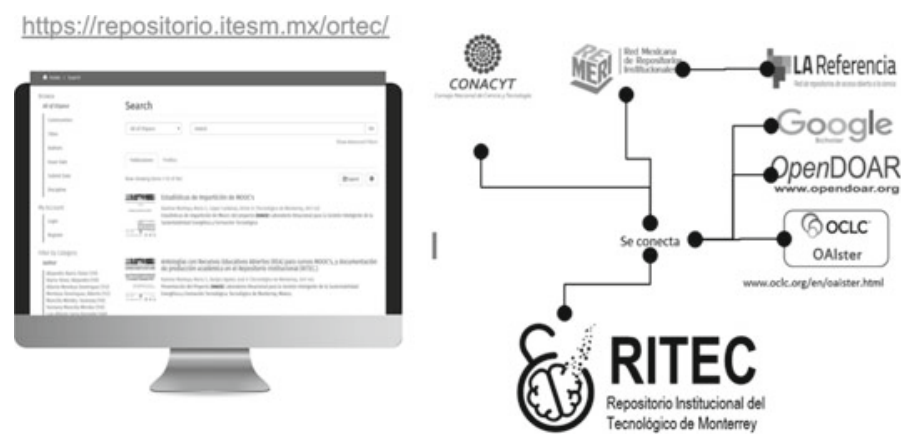

Fig. 10.7 Open science trough RITEC (https://repositorio.itesm.mx/ortec/)

\subsubsection{Open Research Category}

Open research is about research study or initiative about open education and/or related areas. A study or initiative that helps advance our understanding and demonstrate effectiveness related to challenges in discoverability, presentation, usability, accessibility or availability of OER (Open Education Consortium, 2019).

This open research initiative contemplates integrated studies of educational innovation in open mass courses and open repository systems. Research contributes to open education by analyzing the effectiveness of strategies, resources and learning in open environments, as well as the challenges of integrating educational innovation into technological systems, where open platforms and technologies have not yet reached their potential for accessibility, usability and availability of the OER (Ramírez-Montoya, 2019c).

The open research project: studies of educational innovation in the open movement highlights studies that are carried out by researchers, master students and students of two doctoral programs (Mexico and Spain) that participate in the Educational Innovation Research Group, in the Openergy Network and in the UNESCO/ICDE Open Educational Movement for Latin America Chairs.

The research activities are carried out in a network, with collaboration, open knowledge, experimentation and open education research. The results account for 5 graduate students of the Master's program, 3 Ph.D. graduates, 21 articles, 37 proceedings, 8 thesis and 3 books (production available in the open repository of the Tecnologico de Monterrey, link https://tiny.cc/Ritec-RedOpenergy). The focus of the research carried out revolves around the innovations of the MOOCs and the institutional repository where the knowledge generated is preserved and disseminated (Fig. 10.8).

This project contributes to open research with the development of talent, the scientific knowledge of educational innovation in open education, open publications, systematic mapping of literature and systematic reviews of literature. The knowledge generated supports the group of researchers to offer open education products 
Fig. 10.8 Research mapping about project

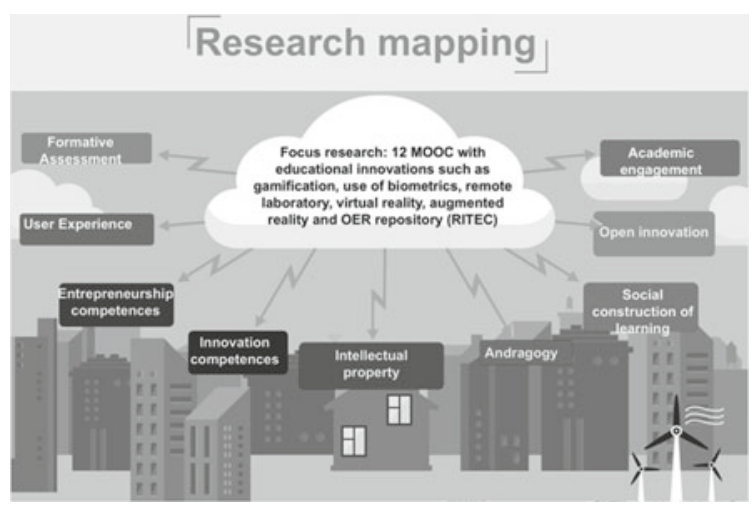

and services, such as educational innovations for open environments with technologies, services and strategies for open science, laboratory for social innovation and consultancy in educational research and open education.

The knowledge generated gives the possibility to open portfolios where knowledge is transferred, through some possibilities such as: training models with technologies, new services for open science, new instruments for measuring innovations OpenLabs, training services: workshops, diplomas, certificates and consultancies, research laboratory and open science in education and sustainable LivingLabs, among others. The transfer can be made to the sectors of the Government, the Companies, Institutions, NGOs and Society in general (Ramírez-Montoya, 2019d).

\subsection{Discussion}

Open innovation (which links the quadruple helix of the academic, governmental, social and economic sectors), is enriched by the integration of gamification, since it provides new opportunities for training institutions. This integration of gaming strategies promotes the motivation of the participants (Brull \& Finlayson, 2016; Chang \& Wei, 2016; Hamari et al., 2016; Hsin, Huang, \& Soman, 2013) and institutional, national and international collaboration (Hormia-Poutanen \& Forsström, 2016). The binational laboratory project was joined by the Federal Electricity Commission, the academy with several universities, civil society (with more than 200,000 participants) and the government (through funding agencies). In this way, open innovation, through MOOCs with gamification, enhances its possibilities for impact and innovation.

Emerging technologies are resources that reinforce the possibilities of open practices and the creativity of the designers is substantial to integrate them in environments where it seems that indexing is not possible. Although some authors have identified tools to work with open knowledge (Rojeski \& Morse, 2016) there is still a lack of experimentation with new technologies to enrich open education. Table 10.1 
shows the integration of virtual reality, augmented reality, biometrics, virtual and remote laboratories into MOOCs, technologies that had not previously been incorporated into MOOCs. Creativity and ingenuity with emerging technologies give new opportunities to establish open education practices.

Open education requires planning strategies to produce and disseminate knowledge, in such a way that its impact is transferable to different areas, beyond where they were generated. The authors agree when they state the need for dynamic and knowledge-based practices (Chesbrough, 2012) as well as the need to share publications and research data to contribute to the advancement of science (AleixandreBenavent et al., 2015). Figure 10.8 presents the map of collaborative research. Likewise, the project presents transference through the training of specialized talent in postgraduates and in the more than 200,000 MOOC participants, as well as in the more than 5000 OER that emanated from the MOOC pieces. Research and open science are presented as mobilizers to reach impact on society.

\subsection{Conclusions}

The open educational movement has an important impulse with the OER; in this impulse, it is possible to create opportunities for constructing educational practices with great reach. One of these reaches has been given through the MOOCs that can have a coverage in the formation and construction of very wide knowledge. The developments of OER and MOOC must take care of the properties of accessibility, scalability and above all of quality, both pedagogical and technological, with a view to achieving contributions of relevance to education.

The question that guided this writing was: What contributions can arise from formative instances such as MOOCs and OER for open education and open science? The results show contributions for open education in the areas:

- Open innovation (through the transfer OER and MOOCs and linkage with Government, Companies, Institutions, NGOs and Civil Society),

- Open research (with educational innovations for open environments with technologies, services and strategies for open science, laboratory for social innovation and consultancy in educational research) and

- Open science (with good practice of collaborative construction and visibility of knowledge, through more than 5000 OER available openly in the Ritec, built in the OpenergyLab, digitized postgraduate theses and OER produced in the binational laboratory, and also, contributed with a protocol for evaluating the user experience of a management model that involves visibility mechanisms of scientific production, thus contributing to incremental innovation with open systems to give visibility to knowledge and open science).

The findings can contribute to academic communities (students, teachers, researchers, administrators), social communities, government, business and decision makers interested in learning environments and open educational practices. The 
chapter is an invitation to continue analyzing the possibilities, impacts and challenges of integrating OER and MOOCs, as well as emerging technologies, especially in areas of the common good such as energy.

Acknowledgments We thank the multidisciplinary team that has worked on this project, their collaboration has been substantial in the transcendence of the achievements. Funding: This chapter is a product of the Project 266632 "Laboratorio Binacional para la Gestión Inteligente de la Sustentabilidad Energética y la Formación Tecnológica" ["Bi-National Laboratory on Smart Sustainable Energy Management and Technology Training"], funded by the CONACYT SENER Fund for Energy Sustainability (Agreement: S0019 $\neg 2014 \neg 01)$.

Conflicts of Interest The author declares no conflict of interest.

\section{References}

Aleixandre-Benavent, R., Ferrer Sapena, A., Alonso-Arroyo, A., Vidal Infer, A., Lucas Domínguez, R., \& González de Dios, J. (2015). Comunicación científica (XXVI). Cómo aumentar la difusión y el impacto de los trabajos pediátricos participando en la ciencia abierta. Acta Pediatr Esp, 73(8), 203-210. Retrieved from http://www.actapediatrica.com/images/pdf/Volumen73-Numero-8-Septiembre-2015.pdf\#page $=33$.

Apostol, S., Zaharescu, L., \& Alexe, I. (2013). Gamification of learning and educational games. Elearning \& Software For Education, 2, 67-72.

Atkins, D., Seely, J., \& Hammond, A. (2007). Report to the William and Flora Hewlett Foundation. Retrieved from http://www.hewlett.org/oer.

Baggaley, J. (2013). MOOC rampant. Distance Education, 34(3), 368-378. https://doi.org/10.1080/ 01587919.2013.835768.

Bartolomé, A. R., \& Steffens, K. (2015). ¿Son los MOOC una alternativa de aprendizaje? Comunicar, 22(44), 91-99. https://doi.org/10.3916/c44-2015-10.

Brull, S., \& Finlayson, S. (2016). Importance of gamification in increasing learning. The Journal of Continuing Education in Nursing, 47(8), 372-375. https://doi.org/10.3928/ 0022012410160715-09.

Cabero, J. C. (2015). Visiones educativas sobre los MOOC. RIED. Revista Iberoamericana de Educación a Distancia, 18(2), 39-60. https://doi.org/10.5944/ried.18.2.13718.

Castaño, C., Maiz, I., \& Garay, U. (2015). Diseño, motivación y rendimiento en un curso MOOC cooperativo. Comunicar, 22(44), 19-26. https://doi.org/10.3916/c44-2015-02.

Chang, J. W., \& Wei, H. Y. (2016). Exploring engaging gamification mechanics in massive online open courses. Journal of Educational Technology \& Society, 19(2), 177-203. Retrieved from http://www.jstor.org/stable/jeductechsoci.19.2.177.

Chesbrough, H. (2012). Open innovation: Where we've been and where we're going. ResearchTechnology Management, 55(4), 20-27. https://doi.org/10.5437/08956308x5504085.

Fidalgo-Blanco, Á., Sein-Echaluce, M. L., \& García-Peñalvo, F. J. (2016). From massive access to cooperation: lessons learned and proven results of a hybrid xMOOC/cMOOC pedagogical approach to MOOCs. International Journal of Educational Technology in Higher Education, 13(1), 24. https://doi.org/10.1186/s41239-016-0024-z.

Gallego-Durán, F. J., Villagrá-Arnedo, C. J., Satorre Cuerda, R., Compañ, P., Molina-Carmona, R., \& Llorens Largo, F. (2014). Panorámica: serious games, gamification y mucho más. ReVisión, 7(2), 13-23. Retrieved from http://hdl.handle.net/10045/37972.

Gassmann, O., Enkel, E., \& Chesbrough, H. (2010). The future of open innovation. $R \& d$ Management, 40(3), 213-221. https://doi.org/10.1111/j.1467-9310.2010.00605.x. 
Hamari, J., Shernoff, D. J., Rowe, E., Coller, B., Asbell-Clarke, J., \& Edwards, T. (2016). Challenging games help students learn: An empirical study on engagement, flow and immersion in game-based learning. Computers in Human Behavior, 54, 170-179. https://doi.org/10.1016/j.chb. 2015.07.045.

Hormia-Poutanen, K., \& Forsström, P. L. (2016). Collaboration at International, National and Institutional Level-Vital in Fostering Open Science. Liber Quarterly, 26(1). Retrieved from https:// www.liberquarterly.eu/articles/10.18352/lq.10157/.

Hsin, W., Huang, Y., \& Soman, D. (2013). A practioner's guide to gamification of education. Research Report Series Behavioural Economics in Action, 29. Retrieved from https://pdfs. semanticscholar.org/c1df/e1970305f257b08a9f2b9844b346452eb869.pdf.

Jeffords, J., Kane, P., Moghaddam, Y., Rucinski, A., \& Temesgen, Z. (2014). Exponentially disruptive innovation driven by service science and the Internet of Things as a Grand Challenge enabler in Education. In 2014 International Conference on Interactive Collaborative Learning (ICL) (pp. 1021-1025). IEEE. https://doi.org/10.1109/icl.2014.7017922.

Littlejohn, A., \& Hood, N. (2017). How educators build knowledge and expand their practice: The case of open education resources. British Journal of Educational Technology, 48(2), 499-510. https://doi.org/10.1111/bjet.12438.

Martin-Rubio, I., Nogueira, J. I., \& Llach-Pages, J. (2013). Open innovation: Leadership and values. Dyna, 88(6), 679-684. https://doi.org/10.6036/5752.

Molina-Gutiérrez, A., Ramírez-Montoya, M. S., Mendoza Domínguez. A., Aldape, L. P., Farías, S. C., \& González del Bosque, S. (2019). Open innovation: energy sustainability training through MOOCs subproject [Document]. Retrieved from http://hdl.handle.net/11285/633011.

Open Education Consortium (2019). Retrieved from https://www.oeconsortium.org/projects/openeducation-awards-for-excellence/2019-winners-of-oe-awards/.

Pirkkalainen, H., Pawlowski, J. M., \& Pappa, D. (2017). Educators' open educational collaboration online: The dilemma of emotional ownership. Computers \& Education, 106, 119-136. https:// doi.org/10.1016/j.compedu.2016.12.005.

Zheng, Q., Chen, L., \& Burgos, D. (2018). Conclusions of construction and development of MOOCs in China. In The development of MOOCs in China (pp. 277-288). Springer, Singapore.

Ramírez-Montoya, M. S. (2018). Innovación abierta, interdisciplinaria y colaborativa para formar en sustentablidad energética a través de MOOCs e investigación educativa. Education in the Knowledge Society (EKS), 19, 11-30. https://doi.org/10.14201/eks20181941130. Retrieved from http:// hdl.handle.net/11285/632776.

Ramírez-Montoya, M. S., \& García-Peñalvo, F. J. (2018). Co-creation and open innovation: Systematic literature review. Comunicar, 26, 09-18. https://doi.org/10.3916/c54-2018-01. Retrieved from https://repositorio.itesm.mx/handle/11285/627964.

Ramírez-Montoya, M. S. (2019a). Open innovation: Energy sustainability training through MOOCs subproject [Video]. Retrieved from https://tiny.cc/OpenInnovation.

Ramírez-Montoya, M. S. (2019b). Best practice in Open Science: The case Bi-National laboratory on smart sustainable energy management and technology training [Video]. Retrieved from https:// tiny.cc/OpenScience.

Ramírez-Montoya, M. S. (2019c). Open Research: Studies of educational innovation in the open movement [Document]. Retrieved from http://hdl.handle.net/11285/633012.

Ramírez-Montoya, M. S. (2019d). Open Research: Studies of educational innovation in the open movement [Video]. Retrieved from https://tiny.cc/OpenResearch.

Ramírez-Montoya, M. S., Burgos Aguilar, J. V., González-Pérez, L. I., \& Ceballos-Cancino, H. G. (2019). Best practice in Open Science: The case Bi-National laboratory on smart sustainable energy management and technology training [Document]. Retrieved from http://hdl.handle.net/ $11285 / 633010$.

Rojeski, M., \& Morse, C. (2016). Keeping your options open: A review of open source and free technologies for instructional use in higher education. Reference Services Review, 44, 375-389. https://doi.org/10.1108/rsr-05-2016-0033. 
Sánchez-Vera, M. M., León-Urrutia, M., \& Davis, H. (2015). Desafíos en la creación, desarrollo e implementación de los MOOC: El curso de Web Science en la Universidad de Southampton. Comunicar, 22(44), 37-44. https://doi.org/10.3916/c44-2015-04.

Schmidt, B., Orth, A., Franck, G., Kuchma, I., Knoth, P., \& Carvalho, J. (2016). Stepping up open science training for European research. Publications, 4(2), 16. https://doi.org/10.3390/ publications4020016.

Shivdas, P. A., \& Sivakumar, S. (2016). Innovation in services: A lancastrian approach to the field of e-learning. Education and Information Technologies, 21(6), 1913-1925. https://doi.org/10.1007/ s10639-015-9427-z.

Teixes, F. (2015). Gamificación: fundamentos y aplicaciones (Vol. 7). España: Editorial UOC.

Veletsianos, G., \& Kimmons, R. (2012). Assumptions and challenges of open scholarship. The International Review of Research in Open and Distributed Learning, 13(4), 166-189. https://doi. org/10.19173/irrodl.v13i4.1313.

Open Access This chapter is licensed under the terms of the Creative Commons Attribution 4.0 International License (http://creativecommons.org/licenses/by/4.0/), which permits use, sharing, adaptation, distribution and reproduction in any medium or format, as long as you give appropriate credit to the original author(s) and the source, provide a link to the Creative Commons license and indicate if changes were made.

The images or other third party material in this chapter are included in the chapter's Creative Commons license, unless indicated otherwise in a credit line to the material. If material is not included in the chapter's Creative Commons license and your intended use is not permitted by statutory regulation or exceeds the permitted use, you will need to obtain permission directly from the copyright holder.

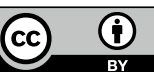

